\title{
Effect of Pt loading on the response of gas sensors
}

\author{
Noel Purcell1,2,3, David Richardson ${ }^{3}$, Stephen Daniels ${ }^{3,4}$, Fernando M.F. Rhen ${ }^{1,2}$ \\ ${ }^{1}$ Department of Physics, University of Limerick, Ireland \\ ${ }^{2}$ Bernal Institute, University of Limerick, Ireland \\ ${ }^{3}$ Ei Electronics, Shannon, Ireland \\ ${ }^{4}$ School of Electronic Engineering, Dublin City University, Ireland \\ *Noel.Purcell@ul.ie
}

\begin{abstract}
The aim of this work is to determine the minimum electrode platinum loading required for the preparation of reliable electrochemical sensors for $\mathrm{CO}$ detection. $\mathrm{Pt}$ is a required constituent of the electrode as it catalyzes the oxygen reduction reaction that occurs in the presence of $\mathrm{CO}$. The Pt loading in the electrodes was varied from $0.2 \mathrm{~g} / \mathrm{cm}^{3}$ to $0.025 \mathrm{~g} / \mathrm{cm}^{3}$. The electrode output shows a minimal decrease as the Pt loading is decreased, until a critical point is reached and output decreases significantly. SEM imaging of the $\mathrm{Pt}$ electrodes indicates that the large decrease in output is caused by a percolation threshold between neighboring Pt clusters as opposed to a limited amount of catalyst. This information can be used to decide the optimal amount of Pt to use per sensor depending on desired output or cost.
\end{abstract}

Key words: Platinum Catalyst, Electrochemical Sensor, Carbon Monoxide Oxidation, Catalyst Loading,

\section{Introduction}

$P t$ is a very effective catalyst used for both oxidation and reduction in electrochemical sensors and fuel cells [1, 2]. It is used almost exclusively in the carbon monoxide (CO) detection industry for oxidizing $\mathrm{CO}$ which occurs through the following equations 1-3.

Working Electrode

$2 \mathrm{CO}+2 \mathrm{H}_{2} \mathrm{O} \rightarrow 2 \mathrm{CO}_{2}+4 \mathrm{H}^{+}+4 \mathrm{e}^{-}$

Counter Electrode

$\mathrm{O}_{2}+4 \mathrm{H}^{+}+4 \mathrm{e}^{-} \rightarrow 2 \mathrm{H}_{2} \mathrm{O}$

Overall reaction

$2 \mathrm{CO}+\mathrm{O}_{2} \rightarrow 2 \mathrm{CO}_{2}$

Stability issues hinder its widespread use in fuel cells and its high costs are a concern in the sensor industry [3]. To alleviate these shortcomings a large amount of research has been carried out into ways of reducing the dependence on $\mathrm{Pt}$ in these technologies [4]. Essential to this will be either reducing the amount of $\mathrm{Pt}$ required or replacing it entirely.

\section{Results}

The output of $\mathrm{CO}$ sensors prepared with varying Pt catalyst densities were measured in 200 ppm
CO gas chamber. Desirable characteristics of a CO sensor include, a quick response time in the presence of $\mathrm{CO}$, a steady output while $\mathrm{CO}$ is present and the fast decrease to the original baseline when the $\mathrm{CO}$ is removed. These are all considered requirements of a sensor used in $\mathrm{CO}$ detection.

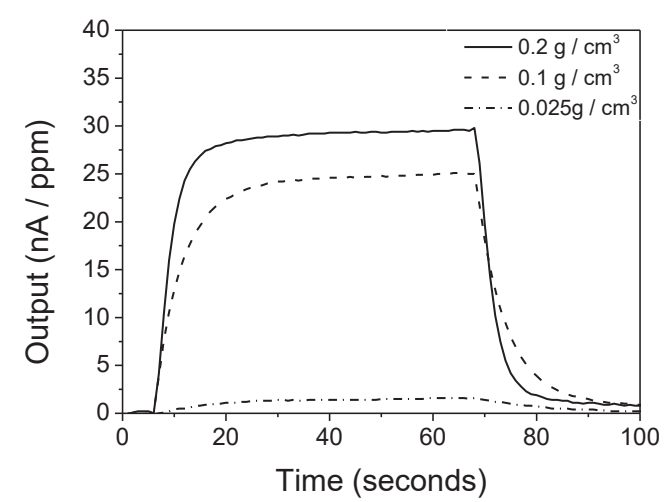

Fig 1. Current output of sensors prepared with varying Pt loading when exposed to $200 \mathrm{ppm}$ CO gas.

Sensors with Pt loadings of $0.2 \mathrm{~g} / \mathrm{cm}^{3}, 0.1 \mathrm{~g} /$ $\mathrm{cm}^{3}$ and $0.025 \mathrm{~g} / \mathrm{cm}^{3}$ are shown in Fig. 1 . These initial results indicate that the output of the sensors does not decrease proportionally with $\mathrm{Pt}$ loading and so it is not the only limiting factor. 
Fig 1 shows that the $\mathrm{CO}$ sensors with a $\mathrm{Pt}$ loading of $0.2 \mathrm{~g} / \mathrm{cm}^{3}$ have an average output of $28 \mathrm{nA} / \mathrm{ppm}$, while sensors with a Pt loading of $0.1 \mathrm{~g} / \mathrm{cm}^{3}$ have an average output of $24 \mathrm{nA} /$ ppm, which means that a $50 \%$ reduction in $\mathrm{Pt}$ loading corresponds to a $14.3 \%$ decrease in current output / ppm. However, there is a change in the rise time of the sensors with lower $\mathrm{Pt}$ loadings. The rise time changes from $15 \mathrm{~s}$ to 25 $\mathrm{s}$ for Pt loadings of $0.2 \mathrm{~g} / \mathrm{cm}^{3}$ and $0.1 \mathrm{~g} / \mathrm{cm}^{3}$.

Fig 1 also shows the output is significantly lowered to $1 \mathrm{nA} / \mathrm{ppm}$ when the Pt density is reduced to $0.025 \mathrm{~g} / \mathrm{cm}^{3}$. A decrease in $\mathrm{Pt}$ density by a factor of 4 causes a decrease in output by a factor of 24 . Initial evidence indicates that as the Pt density decreases the Pt forms clusters that become isolated throughout the electrode.

Fig 2(a) and (b) are SEM images of electrodes with a Pt density of $0.2 \mathrm{~g} / \mathrm{cm}^{3}$, showing uniformly distributed $\mathrm{Pt}$ throughout the electrode, ensuring oxidation and conduction throughout. When the $\mathrm{Pt}$ loading is decreased, the $\mathrm{Pt}$ clusters become isolated and the electrons generated during oxidation at these clusters is not conducted to the external circuit. Therefore, it is likely that a critical Pt density exists at which the output of the electrodes decreases sharply and this paper aims to find the critical Pt loading required for percolation to be maintained.
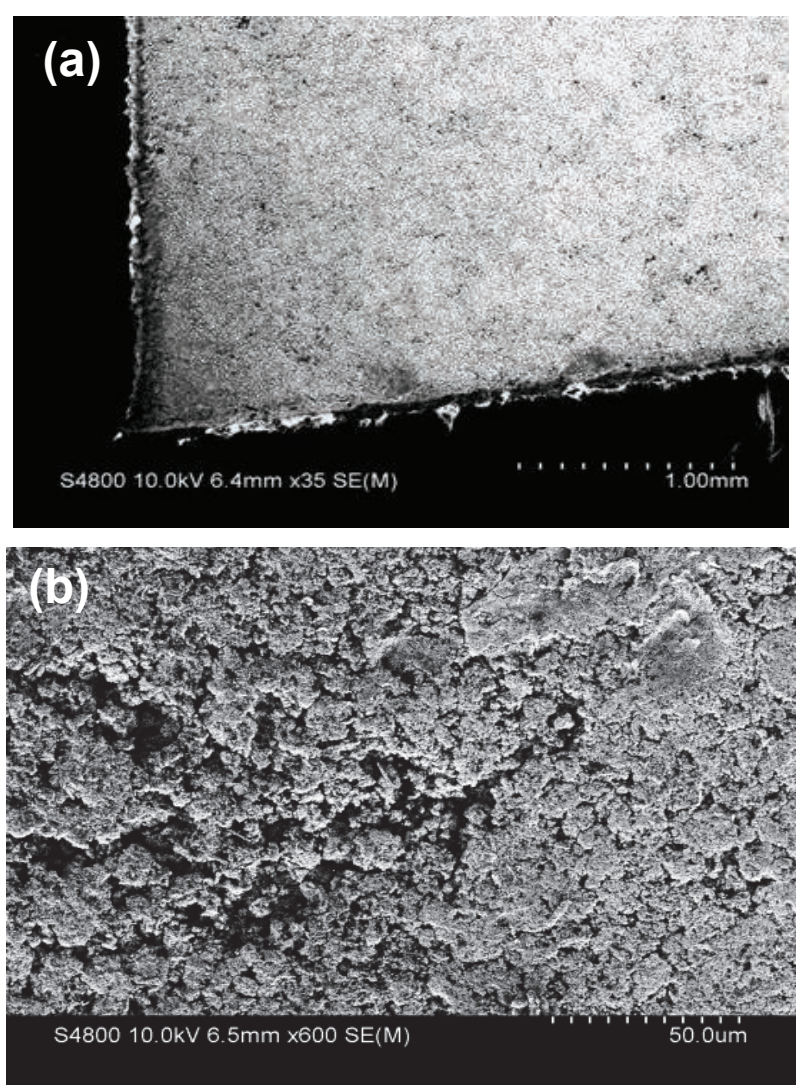

Fig 2. (a) SEM image of Pt density of $0.5 \mathrm{~g} / \mathrm{cm}^{3}$ distribution over the electrode and (b) SEM image of Pt clusters.

\section{Conclusions and Future Work}

We have shown that at high Pt loadings a large reduction in $\mathrm{Pt}$ will have a smaller impact at on output and rise times. The work done indicates that there is a point at which the $\mathrm{Pt}$ will form smaller clusters that are too isolated to function effectively. Further investigation will be carried out for determining the critical loading of $\mathrm{Pt}$ for reliable $\mathrm{CO}$ detection.

\section{References}

[1] K. Kinoshita, J. Electrochem. Soc. 1990, 137, 845

[2] F. M. F. Rhen, C. McKeown, J. Phys. Chem. C, 2017, 121, 2556

[3] Y. L. Yu, Y. P. Hu, X. Liu, W. Q. Deng, X. Wang, Electrochim. Acta 2009, 54, 3092

[4] J. Stacya, Y. N. Regmib, B. Leonardb, M. Fana. Renew. Sustain. Ener. 2017, 69, 401

\section{Acknowledgements}

This work is supported by the Irish Research Council (EBP/2017/435). 